\title{
Outcome of MC3 ring annuloplasty for moderate and severe functional tricuspid regurgitation associated with rheumatic mitral valve disease
}

\author{
Shady Eid Al-Elwany, Yasser Shaban Mubarak and Yasser Ali Kamal ${ }^{*}$ [D
}

\begin{abstract}
Background: To evaluate early and midterm outcomes of tricuspid ring annuloplasty using three-dimensional (3D) MC3 ring for treatment of functional tricuspid regurgitation (FTR) during mitral valve replacement for rheumatic valve disease.

Results: This prospective study included 105 patients who underwent repair for $\geq$ moderate tricuspid regurgitation (TR) during mitral valve replacement for rheumatic valve disease. Between January 2016 and December 2018, a group of 23 patients who underwent ring annuloplasty with Edward MC3 rings was compared to another group of 82 patients who underwent standard suture (DeVega) repair. The primary outcome was residual TR ( $\geq$ moderate TR). During an average follow-up period of $18.84 \pm 9.90$ months (range 3-33 months), the preoperative grade of TR improved significantly in both groups. The postoperative mean of TR in the MC3 group was significantly lower than that in the DeVega group $(0.17 \pm 0.49$ versus $0.77 \pm 0.93, P=0.004)$. The rate of TR recurrence $(\geq 2+T R)$ was significantly higher after MC3 ring annuloplasty (4.3\% versus $23.1 \%, P=0.03$ ). Freedom from mild TR was $30.5 \%$ in the DeVega group and $61 \%$ in the ring annuloplasty group $(P=0.007)$. Freedom from residual TR was $76.8 \%$ in the DeVega group and $95.7 \%$ in the ring annuloplasty group $(P=0.04)$.

Conclusions: The use of MC3 rings is a safe and effective alternative to DeVega repair for the management of FTR. However, further evaluation of long-term durability is recommended.
\end{abstract}

Keywords: Tricuspid valve, Functional tricuspid regurgitation, Suture annuloplasty, Ring annuloplasty

\section{Background}

Functional tricuspid regurgitation (FTR) is a common consequence with mitral valve disease (rheumatic, ischemic, degenerative, or dilated cardiomyopathy), secondary to dilation or dysfunction of the right ventricle, tricuspid annular dilatation, leaflet tethering, atrial fibrillation (AF), or pulmonary hypertension [1]. In patients with rheumatic heart disease (RHD), leaflet thickening and restriction of the tricuspid valve (TV) can result in FTR, but the incidence of organic TV involvement may be higher [2].

\footnotetext{
* Correspondence: Yasser.Ali@mu.edu.eg; yaser_ali_kamal@yahoo.com Department of Cardiothoracic Surgery, Faculty of Medicine, Minia University, El-Minya 61519, Egypt
}

The available guidelines recommend the surgical treatment of severe FTR during valve surgery regardless of the presence of symptoms. However, in less than severe FTR, the decision for surgery is controversial, with a preference for surgery if there is a significant annular dilatation $[1,3]$.

Currently, the surgical techniques for FTR vary from suture repair to implantation of prosthetic rings. Since the first introduction of prosthetic rings for tricuspid annuloplasty in 1971, multiple ring designs have been developed to reinforce the tricuspid annulus by fixing the annulus during systole, restoring the physiologic valve geometry, reducing the annular dilatation, or restoring the 3D morphology [4]. The prosthetic rings for tricuspid annuloplasty have been categorized in 
accordance with the degree of rigidity, the completeness of the circularity, and the dimensionality. Therefore, the prosthetic ring may be rigid or flexible, complete or incomplete, and planar or three dimensional (3D) $[5,6]$.

The MC3 ring (Edwards LifeScience, Irvine, CA, USA), the first $3 \mathrm{D}$ ring, was introduced to restore the geometry of the tricuspid annulus relying on the advantage of accommodating the 3D aspect of the tricuspid annulus [7]. In literature, some studies have reported favorable early outcomes of MC3 rings for the management of FTR during surgery for left-valve disease $[8,9]$.

Generally, there is good evidence supporting ring annuloplasty over De Vega's annuloplasty supporting its use for moderate to severe TR [6]. However, the data still limited regarding the specification of outcomes to the pathology of the heart valve disease and type of prosthetic ring. Therefore, this study aimed to evaluate our own experience with the early and midterm outcomes of tricuspid annuloplasty using MC3 ring for repair of FTR associated with rheumatic mitral valve disease, in comparison to outcomes of suture repair.

\section{Methods}

This prospective study evaluated early and midterm outcomes after operations for TV repair which were performed at our institution, between January 2016 and December 2018. The mean follow-up duration was $18.84 \pm 9.90$ months (range 3-33 months). The study included 105 patients who underwent repair for FTR during mitral valve replacement for rheumatic valve disease. There were 82 patients who underwent suture (DeVega) repair and 23 patients underwent ring annuloplasty using Edward MC3 incomplete 3D ring. The indications of surgery for FTR were (1) severe TR or (2) moderate TR with annular dilatation greater than 40 $\mathrm{mm}$ and/or preoperative systolic pulmonary artery pressure (SPAP) $>50 \mathrm{mmHg}$. We excluded patients with non-rheumatic mitral disease, combined mitral and aortic valve replacement, mitral valve repair, concomitant coronary artery or aortic surgery, mild or organic tricuspid regurgitation, emergency surgery, reoperations, or missed data. Based on echocardiographic data, the severity of TR was graded as 0 (no TR), $1+$ (mild TR), $2+$ (mild to moderate TR), 3+ (moderately severe TR), or $4+$ (severe).

The type of tricuspid valve repair was chosen according to the surgeon's preference and echocardiographic criteria of TV. The DeVega repair was performed when the patient had minimal annular dilation and lower severity of pulmonary hypertension, while ring annuloplasty was performed in patients with severe tricuspid annular dilation and severe pulmonary hypertension. The DeVega repair was performed on a beating heart using pledget-supported two 4-0 polypropylene running parallel sutures. The MC3 ring annuloplasty was performed through right atriotomy using cardiopulmonary bypass and cardioplegic arrest. The ring size was determined after measurement of the length of the attachments of the tricuspid septal leaflet (the distance between the anteroseptal and septoposterior commissures) or the surface area of the anterior leaflet. The chosen ring was undersized by at least one size. The ring was implanted from the anteroseptal commissure to the middle of the septal leaflet. A series of 8 to10 mattress sutures with a 2-0 Ethibond multifilament suture were made on the tricuspid annulus starting from the center of the septal annulus to the anteroseptal commissure in the counter-clockwise direction, to avoid the atrioventricular conduction tissue. Thereafter, the sutures were placed through the sewing ring of the prosthesis (Fig. 1), followed by the lowering and securing of the ring to the annulus (Fig. 2).

The collected preoperative data included age, sex, New York Heart Association (NYHA) functional class, and the type of preoperative mitral valve disease. The primarily assessed postoperative outcome was residual TR $(\geq$ moderate TR; $\geq$ grade +2$)$. Other assessed pre- and postoperative parameters included the NYHA functional class and echocardiographic data regarding the grade of TR, SPAP, tricuspid annulus (TA) diameter, tricuspid annular plane systolic excursion (TAPSE), left atrial diameter (LAD), left ventricular end-diastolic dimension (LVEDD), left ventricular end-systolic dimension (LVESD), and left ventricular ejection fraction (LVEF).

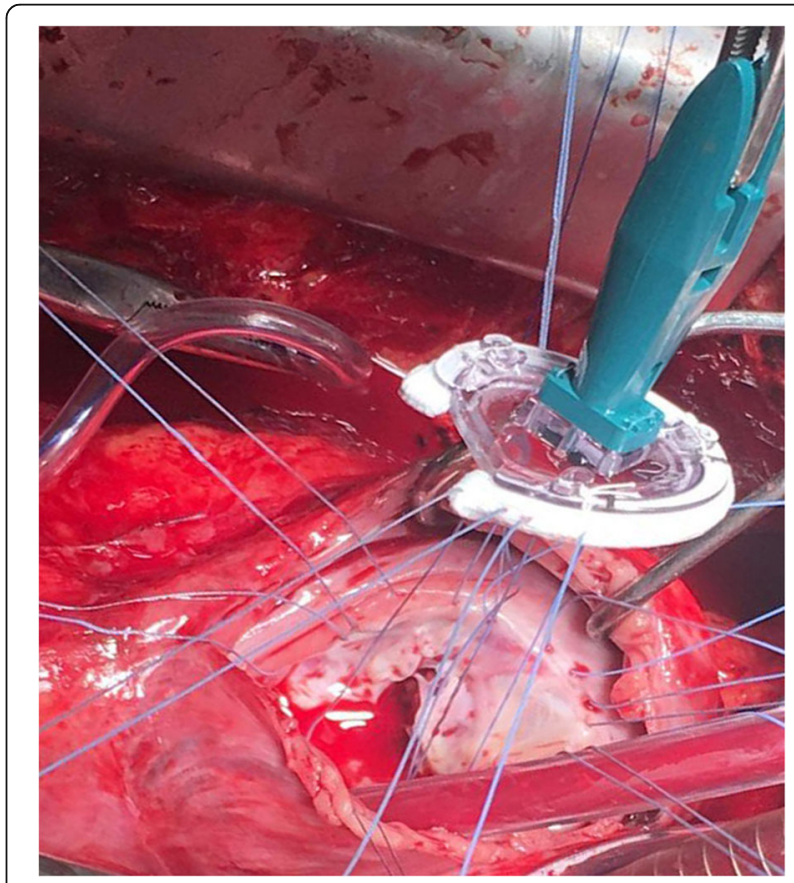

Fig. 1 Intra-operative view of the placement of the sutures through the sewing ring of the MC3 prosthesis 


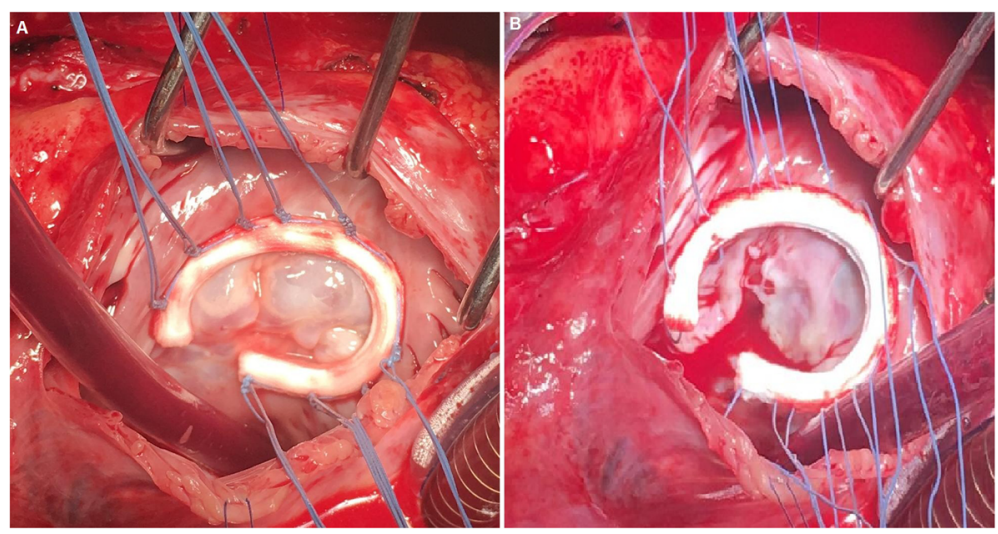

Fig. 2 Intra-operative view of lowering and securing of the MC3 ring to the tricuspid annulus. a During systole. b During diastole

\section{Statistical analysis}

The statistical analysis was performed using the SPSS software package (version 20.0; SPSS Inc., Chicago, IL, USA). The analyzed data were expressed as mean and standard deviation or as proportions. The studied groups were compared using the unpaired Student's $t$ test for continuous independent variables and paired $t$ test to compare related measurements. The categorical variables were compared using chi-squared test or Fisher's exact test if the expected frequency is less than 5. The Kaplan-Meier method was used to determine freedom from residual TR at the end of follow-up. $P$ value $<0.05$ was considered statistically significant.

\section{Results}

Preoperative demographic and clinical characteristics were similar between both groups (Table 1). There was a significant improvement in the preoperative grade of TR following surgery in each group (Fig. 3). There was no significant difference in the preoperative echocardiographic parameters between both groups of tricuspid annuloplasty regarding the grade of TR, SPAP, TA diameter, TAPSE, LAD, LVEDD, LVESD, and LVEF (Table 1).

Regarding comparisons of postoperative and baseline preoperative echocardiographic measurements in each group, there was a significant decrease in the mean of TR grade, SPAP, TA diameter, LAD, and LVESD in both groups, with a significant increase in the mean of LVEDD and LVEF. Moreover, there was a significant increase in the mean of postoperative TAPSE after MC3 ring annuloplasty (Table 2). Comparing the postoperative echocardiographic measurements between both groups revealed non-significant differences, except for the postoperative mean of TR in the MC3 group which was significantly lower than that in the DeVega repair group $(0.17 \pm 0.49$ versus $0.77 \pm 0.93, P=0.004)$ (Table 3$)$. The postoperative frequency of patients without TR (grade 0) in the MC3 group was significantly higher than that in the DeVega repair group (87\% versus $51.2 \%, P=$ $0.002)$. The rate of TR recurrence $(\geq 2+$ TR) was significantly higher after MC3 ring annuloplasty (4.3\% versus $23.1 \%, P=0.03$ ) (Table 4).

Regarding operative data and early postoperative outcomes (Table 5), the group of MC3 ring annuloplasty had significantly higher cardiopulmonary bypass (CPB) time $(128.8 \pm 24.7 \mathrm{~min}$ versus $141.9 \pm 28.4 \mathrm{~min}, P=0.03)$ and cross-clamp time $(71.8 \pm 23.7$ min versus $84.3 \pm 19.2$

Table 1 Preoperative demographic, clinical, and echocardiographic data

\begin{tabular}{llll}
\hline Variables & $\begin{array}{l}\text { DeVega }(n= \\
82)\end{array}$ & $\begin{array}{l}\text { MC3 ring }(n= \\
23)\end{array}$ & $\begin{array}{l}P \\
\text { value }\end{array}$ \\
\hline Age (years) & $48 \pm 11.8$ & $46.2 \pm 11.2$ & 0.53 \\
Female gender & $53(64.6 \%)$ & $14(60.9 \%)$ & 0.74 \\
NYHA class (III/IV) & $52(63.4 \%)$ & $16(69.6 \%)$ & 0.58 \\
Atrial fibrillation & $45(54.9 \%)$ & $13(56.6 \%)$ & 0.88 \\
Mitral valve disease & & & \\
$\quad$ Stenosis & $18(23.2 \%)$ & $6(26.1 \%)$ & 0.68 \\
$\quad$ Insufficiency & $25(30.5 \%)$ & $4(17.4 \%)$ & 0.29 \\
$\quad$ Stenosis and & $38(46.3 \%)$ & $13(56.5 \%)$ & 0.38 \\
$\quad$ insufficiency & & & \\
Preoperative TR grade & $2.55 \pm 0.61$ & $2.39 \pm 0.65$ & 0.28 \\
SPAP (mmHg) & $47.87 \pm 14.70$ & $52.21 \pm 15.43$ & 0.21 \\
TA diameter (mm) & $34.62 \pm 5.33$ & $34.56 \pm 5.56$ & 0.96 \\
TAPSE (mm) & $18.23 \pm 3.11$ & $17.13 \pm 2.76$ & 0.12 \\
LAD (mm) & $42.97 \pm 4.10$ & $42.13 \pm 4.33$ & 0.39 \\
LVEDD (mm) & $42.34 \pm 2.37$ & $42.08 \pm 2.87$ & 0.66 \\
LVESD (mm) & $34.32 \pm 1.79$ & $34.21 \pm 1.47$ & 0.78 \\
LVEF (\%) & $55.73 \pm 8.93$ & $55.13 \pm 9.45$ & 0.77 \\
\hline NYHA New York Heat Assoi & & & \\
\hline
\end{tabular}

NYHA New York Heart Association, TR tricuspid regurgitation, SPAP systolic pulmonary artery pressure, TA tricuspid annulus, TAPSE tricuspid annular plane systolic excursion, $L A D$ left atrial diameter, $L V E D D$ left ventricular end-diastolic dimension, LVESD left ventricular end-systolic dimension, LVEF left ventricular ejection fraction 

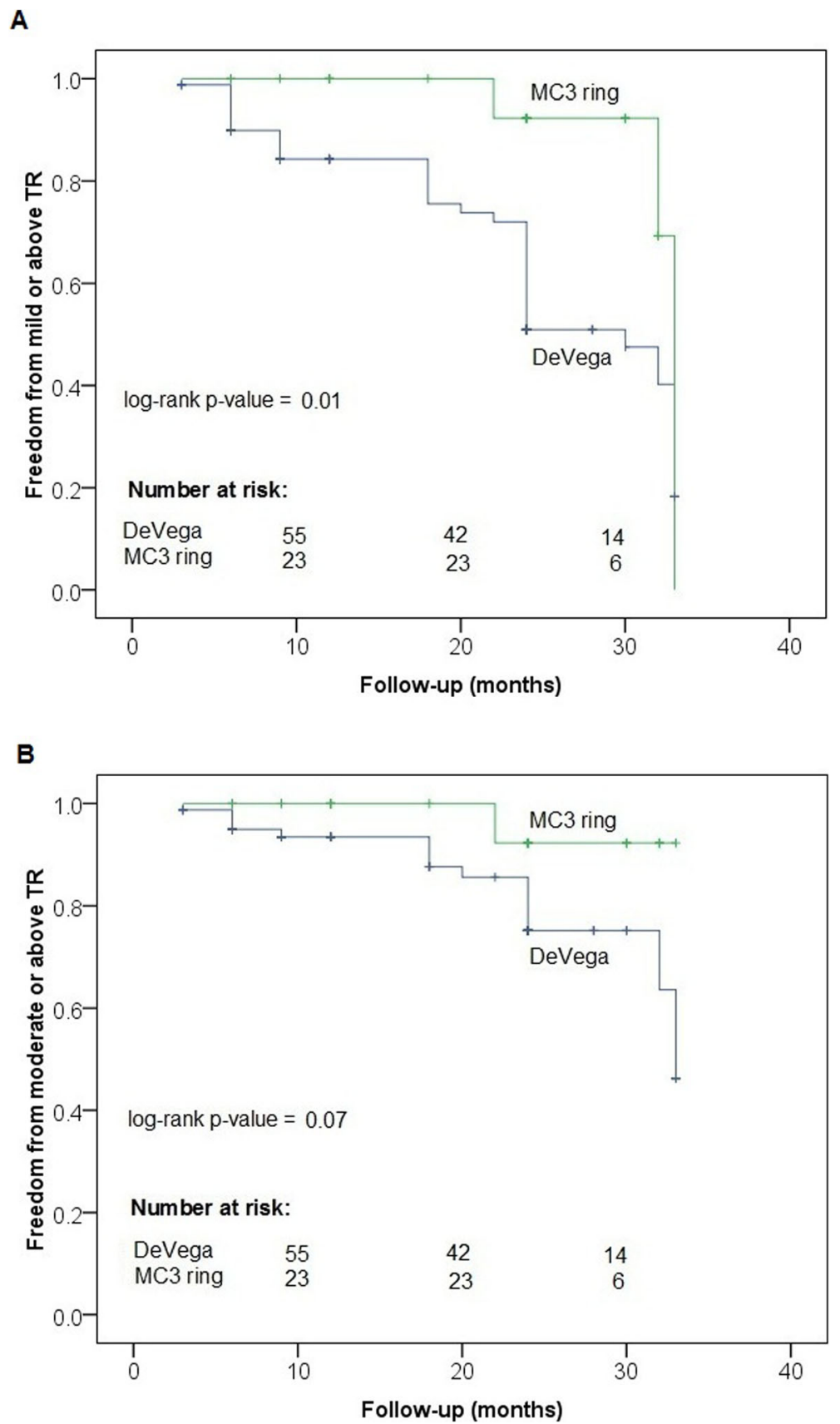

Fig. 3 a Freedom from $\geq$ mild tricuspid regurgitation (TR) after DeVega repair and MC3 ring annuloplasty. $\mathbf{b}$ Freedom from $\geq$ moderate tricuspid regurgitation (TR) after DeVega repair and MC3 ring annuloplasty

min, $P=0.02$ ). There were no significant differences between both groups regarding the need for postoperative intraaortic balloon pump (IABP) support $(2.4 \%$ versus $4.3 \%)$ and the incidence of heart block $(1.2 \%$ versus 8.7\%). During the follow-up period, freedom from mild TR was $30.5 \%$ in the DeVega group and $61 \%$ in the ring annuloplasty group $(P=0.007)$ (Fig. 3a). Freedom from residual TR was $76.8 \%$ in the DeVega group and $95.7 \%$ in the ring annuloplasty group $(P=0.04)$ (Fig. $3 b)$.

\section{Discussion}

The repair of FTR in patients undergoing left heart valve surgery has a controversy among surgeons in terms of timing for intervention and technique of repair [10]. However, the persistence of moderate and severe TR after mitral valve surgery may lead to progressive heart failure or death [11].

The DeVega suture repair is the most commonly used technique of TV repair. However, high recurrence rates 
Table 2 Mean difference between follow-up and preoperative echocardiographic data in relation to the type of tricuspid repair

\begin{tabular}{|c|c|c|c|c|}
\hline \multirow{2}{*}{$\begin{array}{l}\text { Echocardiographic } \\
\text { variables }\end{array}$} & \multicolumn{2}{|c|}{ DeVega $(n=82)$} & \multicolumn{2}{|c|}{ MC3 ring $(n=23)$} \\
\hline & $\begin{array}{l}\text { Mean } \\
\text { difference }\end{array}$ & $P$ value & $\begin{array}{l}\text { Mean } \\
\text { difference }\end{array}$ & $P$ value \\
\hline TR grade & -1.78 & $\begin{array}{l}< \\
0.001^{*}\end{array}$ & -2.22 & $\begin{array}{l}< \\
0.001^{*}\end{array}$ \\
\hline SPAP $(\mathrm{mmHg})$ & -15.35 & $\begin{array}{l}< \\
0.001^{*}\end{array}$ & -18.95 & $\begin{array}{l}< \\
0.001 *\end{array}$ \\
\hline TA diameter (mm) & -4.20 & $\begin{array}{l}< \\
0.001^{*}\end{array}$ & -4.78 & $0.001^{*}$ \\
\hline TAPSE (mm) & +0.66 & 0.17 & +1.87 & $0.02^{*}$ \\
\hline $\operatorname{LAD}(\mathrm{mm})$ & -10.54 & $\begin{array}{l}< \\
0.001^{*}\end{array}$ & -8.96 & $\begin{array}{l}< \\
0.001^{*}\end{array}$ \\
\hline LVEDD (mm) & +0.16 & $0.001^{*}$ & +2.22 & $0.002^{*}$ \\
\hline LVESD (mm) & -1.28 & $\begin{array}{l}< \\
0.001^{*}\end{array}$ & -1.78 & $\begin{array}{l}< \\
0.001 *\end{array}$ \\
\hline LVEF (\%) & +10.63 & $\begin{array}{l}< \\
0.001^{*}\end{array}$ & +16.04 & $\begin{array}{l}< \\
0.001^{*}\end{array}$ \\
\hline
\end{tabular}

$T R$ tricuspid regurgitation, SPAP systolic pulmonary artery pressure, $T A$ tricuspid annulus, TAPSE tricuspid annular plane systolic excursion, $L A D$ left atrial diameter, LVEDD left ventricular end-diastolic dimension, LVESD left ventricular end-systolic dimension, $L V E F$ left ventricular ejection fraction * Significant difference between follow-up and preoperative values within the same group

have been reported with DeVega repair, particularly in patients with severe tricuspid annular dilation and/or pulmonary hypertension [12]. To overcome this issue, the search focused on the use of more anatomically relevant techniques for the management of FTR. For this purpose, ring annuloplasty has been used in the tricuspid position and achieved better results than suture repair [13-15]. The nonplanar, saddle-shaped, 3D structure, the tricuspid annulus favors the use of MC3 ring annuloplasty since its introduction in 2004 [16].

Table 3 Comparison of postoperative echocardiographic between types of tricuspid repair

\begin{tabular}{llll}
\hline $\begin{array}{l}\text { Echocardiographic } \\
\text { variables }\end{array}$ & $\begin{array}{l}\text { DeVega } \\
(n=82)\end{array}$ & $\begin{array}{l}\text { MC3 ring } \\
(n=23)\end{array}$ & $P$ value \\
\hline TR grade & $0.77 \pm 0.93$ & $0.17 \pm 0.49$ & $0.004^{*}$ \\
SPAP $(\mathrm{mmHg})$ & $32.52 \pm 7.50$ & $33.26 \pm 8.83$ & 0.69 \\
TA diameter $(\mathrm{mm})$ & $30.42 \pm 2.99$ & $29.78 \pm 3.20$ & 0.37 \\
TAPSE $(\mathrm{mm})$ & $18.89 \pm 2.55$ & $19 \pm 2.81$ & 0.85 \\
LAD $(\mathrm{mm})$ & $32.43 \pm 4.71$ & $33.17 \pm 5.22$ & 0.52 \\
LVEDD $(\mathrm{mm})$ & $43.50 \pm 2.04$ & $44.30 \pm 1.22$ & 0.07 \\
LVESD $(\mathrm{mm})$ & $33.04 \pm 1.46$ & $32.43 \pm 0.99$ & 0.06 \\
LVEF $(\%)$ & $66.35 \pm 2.07$ & $66.73 \pm 2.11$ & 0.43 \\
\hline
\end{tabular}

$T R$ tricuspid regurgitation, SPAP systolic pulmonary artery pressure, TA tricuspid annulus, TAPSE tricuspid annular plane systolic excursion, $L A D$ left atrial diameter, $L V E D D$ left ventricular end-diastolic dimension, $L V E S D$ left ventricular end-systolic dimension, LVEF left ventricular ejection fraction *Significant difference between follow-up and preoperative values within the same group
Our study compared early and midterm outcomes after MC3 ring annuloplasty in 23 patients with outcomes after DeVega repair in 82 patients, over an average follow-up period of $18.84 \pm 9.90$ months (range 3-33 months). We included patients with severe FTR or moderate TR with severe annular dilatation greater and/ or pulmonary hypertension, and our primary outcome was residual TR ( $\geq$ moderate TR) during the follow-up period. The main findings in the present study are (1) the improvement of midterm echocardiographic parameters in both groups of tricuspid repair on comparison to preoperative values and (2) the superiority of MC3 ring annuloplasty in regards to lower postoperative grade of TR $(0.17 \pm 0.49$ versus $0.77 \pm 0.93, P=0.004)$, lower recurrence rate of $\geq 2+\mathrm{TR}(4.3 \%$ versus $23.1 \%, P=0.03)$, and higher midterm freedom from mild $(61 \%$ versus $30.5 \%, P=0.007)$ and moderate TR $(95.7 \%$ versus $76.8 \%$, $P=0.04$ ). Additionally, we had acceptable incidences of heart block and postoperative use of IABP, beside the midterm absence of ring dehiscence, prosthetic ring endocarditis, and thromboembolic events.

Our favorable and superior outcomes after MC3 ring annuloplasty are comparable to other studies in literature $[7-9,16,17]$. The early study by Filsoufi et al. [7] included 75 patients with FTR with mean TR grade of $3.1 \pm 0.9$ and concomitant procedures of mitral valve repair, replacement, aortic valve replacement, coronary artery bypass grafting, and left atrial maze. The echocardiographic study demonstrated a stable significant decrease in TR $(0.3 \pm 0.5)$ after a median follow-up of 16 months (range 4-34), with no cases of ring dehiscence, prosthetic ring endocarditis, or thromboembolic events. The echocardiographic follow-up study by Fukuda et al. [16] of 136 patients with FTR confirmed the significant improvement in the severity of TR early after surgery and TR graded greater than moderate in 14\% among patients followed more than 1 year. However, additional maneuvers to ensure valve competence were required in patients with extensive leaflet tethering. Jeong and Kim [8] investigated the clinical performance of MC3 rings in 103 patients with an average preoperative TR grade of $2.5 \pm 0.8$, during a mean follow-up of $26.7 \pm 11.2$ (range $0-52$ ) months. The TR grade significantly decreased from $2.5 \pm 0.8$ preoperatively to $0.8 \pm 0.8$ before discharge $(P<0.001)$, which was stable through a median follow-up of 15 months. Additionally, there was a significant improvement in systolic pulmonary artery pressure. Moreover, comparing the outcomes of tricuspid annuloplasty with 3D-rigid versus flexible prosthetic ring for FTR in the study by Wang et al. [17] revealed that MC3 might be more effective for tricuspid ring annuloplasty in FTR in midterm postoperative periods regarding recurrence of TR in $30.3 \%$ of the rigid group versus $54.3 \%$ of the flexible group. 
Table 4 Grades of tricuspid regurgitation at the last follow-up visit

\begin{tabular}{|c|c|c|c|c|c|}
\hline \multirow[t]{2}{*}{ Grades } & \multicolumn{2}{|c|}{ DeVega $(n=82)$} & \multicolumn{2}{|c|}{ MC3 ring $(n=23)$} & \multirow[t]{2}{*}{$P$ value } \\
\hline & $N(\%)$ & $\begin{array}{l}\text { Mean follow-up } \\
\text { (months) }\end{array}$ & $N(\%)$ & $\begin{array}{l}\text { Mean follow-up } \\
\text { (months) }\end{array}$ & \\
\hline 0 & $\begin{array}{l}42 \\
(51.2 \%)\end{array}$ & $23.5 \pm 1.24$ & $\begin{array}{l}20 \\
(87 \%)\end{array}$ & $20.5 \pm 2$ & $0.002^{*}$ \\
\hline $1+$ & $\begin{array}{l}21 \\
(25.6 \%)\end{array}$ & $28.3 \pm 1$ & $\begin{array}{l}2 \\
(8.7 \%)\end{array}$ & $32.7 \pm 0.3$ & 0.09 \\
\hline $2+$ & $\begin{array}{l}16 \\
(19.5 \%)\end{array}$ & $29.6 \pm 0.92$ & $\begin{array}{l}1 \\
(4.3 \%)\end{array}$ & $32.1 \pm 0.18$ & 0.11 \\
\hline $3+$ & $\begin{array}{l}2 \\
(2.4 \%)\end{array}$ & $32.7 \pm 0.22$ & $\begin{array}{l}0 \\
(0 \%)\end{array}$ & - & 1 \\
\hline $4+$ & $\begin{array}{l}1 \\
(1.2 \%)\end{array}$ & $32.6 \pm 0.34$ & $\begin{array}{l}0 \\
(0 \%)\end{array}$ & - & 1 \\
\hline
\end{tabular}

SD standard deviation

*Significant difference

Overall, the midterm durability of MC3 rings and the superiority of the MC3 ring annuloplasty over the DeVega suture repair determined in our study and in other studies could be related to the superiority of the ring in remodeling of the TV annulus effectively compared to suture repair. Remodeling of the TV annulus could decrease the tension on suture lines, increase the leaflet coaptation, and prevent the recurrence of annular dilatation $[18,19]$.

Some authors investigated the predictors of midterm residual TR after MC3 ring annuloplasty [9, 20]. Little number of patients in our study was against multivariate regression analysis, but mentioning the results of these studies may be helpful for proper selection of patients for other surgical interventions with MC3 rings. Yoda et al. [9] investigated the midterm outcomes of MC3 ring in 136 patients with severe TR, or mild or moderate TR with pulmonary hypertension or TA dilatation. Although, the MC3 ring was effective for the correction of FTR, preoperative severe TR, left ventricular enddiastolic dimension $>70 \mathrm{~mm}$, right ventricular dimension $>40 \mathrm{~mm}$, dilated cardiomyopathy (DCM), and left ventriculoplasty associated with repair failure and residual TR. In the study by De Bonis et al. [20] tricuspid annuloplasty with the MC3 ring provided satisfactory

Table 5 Operative data and early postoperative outcomes

\begin{tabular}{llll}
\hline Variables & $\begin{array}{l}\text { DeVega } \\
(n=82)\end{array}$ & $\begin{array}{l}\text { MC3 ring } \\
(n=23)\end{array}$ & $P$ value \\
\hline CBP time (min) & $128.8 \pm 24.7$ & $141.9 \pm 28.4$ & $0.03^{*}$ \\
Cross-clamp time (min) & $71.8 \pm 23.7$ & $84.3 \pm 19.2$ & $0.02^{*}$ \\
Postoperative IABP support & $2(2.4 \%)$ & $1(4.3 \%)$ & 1 \\
Heart block & $1(1.2 \%)$ & $2(8.7 \%)$ & 0.11
\end{tabular}

$C P B$ cardiopulmonary bypass, IABP intraaortic balloon pump

*Significant difference early results in 135 patients which remain stable at midterm follow-up of $22 \pm 9.5$ months (median 23 months). Those authors reported that the presence of other mechanisms besides annular dilatation (leaflet prolapse, pace-maker wires, and fibrotic leaflets' retraction) leads to residual TR after ring annuloplasty alone.

Interestingly, some authors developed certain methods in order to reduce the residual TR after MC3 ring annuloplasty, such as the placement of horizontal mattress sutures on the annulus beyond the anteroseptal commissure and away from the deemed atrioventricular node artery/vein [21], adjustment the point of fixation of the septal portion to the septal annulus [22], and septal plication technique [23]. These modifications are not the concern of our study, but its promising results encourage us to recommend its evaluation in the future studies.

In the present study, our finding of a significant increase in the postoperative TAPSE after MC3 ring annuloplasty in comparison to the preoperative values reflects more preservation of the global right ventricular function with MC3 rings. TAPSE is a parameter of global RV function which describes apex-to-base shortening. TAPSE correlates closely with the RVEF and has been found to be both highly specific and easy to measure [24].

\section{Study limitations}

This study is limited by being a single center experience, including a small number of patients. Moreover, the surgeon's preference directed the choice between DeVega repair and ring annuloplasty. Also, other types of annuloplasty rings were not available at our institution, and thus, it could not be compared to the 3D ring annuloplasty.

\section{Conclusions}

In conclusion, the low incidence of midterm residual TR and the preservation of the global right ventricular function after tricuspid annuloplasty using MC3 for FTR encourage its substitution to the traditional DeVega repair in patients with rheumatic mitral valve disease. However, there is a need to check its durability in longterm and randomized studies.

Abbreviations

AF: Atrial fibrillation; COPD: Chronic obstructive pulmonary disease; DM: Diabetes mellitus; FTR: Functional tricuspid regurgitation; LA: Left atrium; LAD: Left atrial diameter; LVEDD: Left ventricular end-diastolic dimension; LVEF: Left ventricular ejection fraction; LVEF: Left ventricular ejection fraction; LVESD: Left ventricular end-systolic dimension; NYHA: New York Heart Association; RHD: Rheumatic heart disease; SPAP: Systolic pulmonary artery pressure; TA: Tricuspid annulus; TAPSE: Tricuspid annular plane systolic excursion; TR: Tricuspid regurgitation; TV: Tricuspid valve 


\section{Authors' contributions}

SEA conceived and planned the study and supervised the findings of the work. YSM conceived of the study, participated in its design and coordination, and helped to draft the manuscript. YAK participated in the design of the study, carried out the collection of the data and drafting the manuscript, and performed the statistical analysis. All authors cared for the patients. All authors read and approved the final manuscript.

\section{Funding}

The authors declare that they did not receive any funding.

\section{Availability of data and materials}

The datasets used and/or analyzed during the current study are available from the corresponding author on reasonable request.

\section{Ethics approval and consent to participate}

This work was approved by an internal committee under the supervision of the head of departments of surgery at our institution. Additionally, we adhered to a set of ethical principles in the Declaration of Helsinki regarding human experimentation. A written consent to participate was taken from al patients. The manuscript has a reference number of 62-15 and it has been registered in ClinicalTrials.gov under number of NCT04078867.

\section{Consent for publication}

It was taken from patients.

\section{Competing interests}

The authors declare that they have no competing interests.

Received: 5 June 2019 Accepted: 23 September 2019

Published online: 21 November 2019

\section{References}

1. Pozzoli A, Lapenna E, Vicentini L, Alfieri O, De Bonis M (2016) Surgical indication for functional tricuspid regurgitation at initial operation_ judging from long term outcomes. Gen Thorac Cardiovasc Surg 64(9):509

2. Shiran A, Sagie A (2009) Tricuspid regurgitation in mitral valve disease: incidence, prognostic implications, mechanism, and management. J Am Coll Cardiol 53(5):401-408

3. Nishimura RA, Otto CM, Bonow RO, Carabello BA, Erwin JP 3rd, Guyton RA et al (2014) AHA/ACC guideline for the management of patients with valvular heart disease: executive summary: a report of the American College of Cardiology/American Heart Association Task Force on Practice Guidelines. J Am Coll Cardiol 63(22):2438-2488

4. Belluschi I, Del Forno B, Lapenna E, Nisi T, laci G, Ferrara D et al (2018) Surgical techniques for tricuspid valve disease. Front Cardiovasc Med 5:118

5. Lee SI, Kim HJ, Kim JB, Jung SH, Choo SJ, Chung CH et al (2017) Medtronic Duran AnCore versus Edwards MC3 rings for tricuspid annuloplasty. Interact Cardiovasc Thorac Surg 24(6):848-854

6. Khorsandi M, Banerjee A, Singh H, Srivastava AR (2012) Is a tricuspid annuloplasty ring significantly better than a De Vega's annuloplasty stitch when repairing severe tricuspid regurgitation? Interact Cardiovasc Thorac Surg 15(1):129-135

7. Filsoufi F, Salzberg SP, Coutu M, Adams DH (2006) A three dimensional ring annuloplasty for the treatment of tricuspid regurgitation. Ann Thorac Surg 81:2273-2278

8. Jeong DS, Kim KH (2010) Tricuspid annuloplasty using the MC3 ring for functional tricuspid regurgitation. Circ J 74:278-283

9. Yoda M, Tanabe H, Kadoma Y, Suma H (2011) Mid-term results of tricuspid annuloplasty using the MC3 ring for secondary tricuspid valve regurgitation. Interact Cardiovasc Thorac Surg 13:7-10

10. Khallaf AN, Saleh HZ, Elnaggar AM, Rasekh FS (2016) Tricuspid valve repair by DeVega technique versus ring annuloplasty in patients with functional severe tricuspid regurge. J Egypt Soc Cardio Thorac Surg 24:131-134

11. Munasur M, Naidoo D (2016) Underlying rheumatic disease: an important determinant of outcome in tricuspid valve repair. J Heart Valve Dis 25(2): 203-210

12. Rivera R, Duran E, Ajuria M (1985) Carpentier's flexible ring versus De Vega's annuloplasty. A prospective randomized study. J Thorac Cardiovasc Surg 89: 196-203
13. Gatti G, Maffei G, Lusa AM, Pugliese P (2001) Tricuspid valve repair with the Cosgrove-Edwards annuloplasty system: early clinical an echocardiographic results. Ann Thorac Surg 72:764-767

14. Onoda K, Yasuda F, Takao M, Shimono T, Tanaka K, Shimpo H et al (2000) Long-term follow-up after Carpentier-Edwards ring annuloplasty for tricuspid regurgitation. Ann Thorac Surg 70:796-799

15. Tang GL, David TE, Singh SK, Maganti MD, Armstrong S, Borger MA (2006) Tricuspid valve repair with an annuloplasty ring results in improved longterm outcomes. Circulation 114(Suppl I):I-577-|-581

16. Fukuda S, Saracino G, Matsumura Y, Daimon M, Tran H, Greenberg NL et al (2006) Three-dimensional geometry of the tricuspid annulus in healthy subjects and in patients with functional tricuspid regurgitation: a real-time, 3-dimensional echocardiographic study. Circulation 114:1492-1498

17. Wang H, Liu X, Wang X, LV Z, Liu X, Xu P (2016) Comparison of outcomes of tricuspid annuloplasty with 3D-rigid versus flexible prosthetic ring for functional tricuspid regurgitation secondary to rheumatic mitral valve disease. J Thorac Dis 8(11):3087-3095

18. Carpentier A, Deloche A, Dauptain J, Soyer R, Blondeau P, Piwnica A et al (1971) A new reconstructive operation for correction of mitral and tricuspid insufficiency. J Thorac Cardiovasc Surg 61:1-13

19. Guenther T, Mazzitelli D, Noebauer C, Hettich I, Tassani-Prell P, Voss B et al (2013) Tricuspid valve repair: is ring annuloplasty superior? Eur J Cardiothorac Surg 43:58-65

20. De Bonis M, Lapenna E, Taramasso M, Manca M, Calabrese MC, Buzzatti N et al (2012) Mid-term results of tricuspid annuloplasty with a threedimensional remodelling ring. J Card Surg 27(3):288-294

21. Hata H, Fujita T, Shimahara Y, Sato S, Kobayashi J (2014) Early and mid-term outcomes of aggressive tricuspid annuloplasty with the MC3 ring. J Heart Valve Dis 23(5):601-608

22. Isomura T, Hirota M, Hoshino J, Fukada Y, Kondo T, Takahashi Y (2015) Tricuspid annuloplasty with the MC3 ring and septal plication technique. Asian Cardiovasc Thorac Ann 23(1):5-10

23. Kawaura H, Aoki A, Omoto T, Maruta K, lizuka H (2015) Effect of the septal adjustment technique for tricuspid annuloplasty with an MC3 ring. Gen Thorac Cardiovasc Surg 63(5):273-278

24. Ueti OM, Camargo EE, Ueti Ade A, de Lima-Filho EC, Nogueira EA (2002) Assessment of right ventricular function with Doppler echocardiographic indices derived from tricuspid annular motion: comparison with radionuclide angiography. Heart 88(3):244-248

\section{Publisher's Note}

Springer Nature remains neutral with regard to jurisdictional claims in published maps and institutional affiliations.

\section{Submit your manuscript to a SpringerOpen ${ }^{\odot}$ journal and benefit from:}

- Convenient online submission

- Rigorous peer review

- Open access: articles freely available online

- High visibility within the field

- Retaining the copyright to your article

Submit your next manuscript at $>$ springeropen.com 